\section{Epithelial-Mesenchymal Transition and LOXL2: Consideration Continues}

\section{TO THE EDITORS:}

We appreciate the interest in our recent publication in the Annals of Surgical Oncology. ${ }^{1}$ We thank Clara Balsano and colleagues for their comments.

As a new promoter of EMT, LOXL2 is found in several epithelial cancer cell lines. We found that LOXL2 was highly expressed in cholangiocarcinoma (CC) tissues and was associated with $\mathrm{CC}$ invasion and metastasis through EMT. Accordingly, we provided evidence for the hypothesis that $\mathrm{HCV}$ c can promote EMT in CC cell through LOXL2. We estimate that the mechanism may have two aspects: on the one hand, HCVc may interact with LOXL2, making its expression atopic and increasing its activity; on the other hand, HCVc may promote LOXL2 transcription.

Many results support LOXL2 as a new poor prognosis marker or novel therapeutic target in squamous cell carcinomas and gastric cancer. ${ }^{2,3}$ LOXL2 promotes migration in noninvasive breast cancer cells but not in normal breast epithelial cells. $^{4}$

Furthermore, LOXL2 activity might be a crucial modulator of Snail, providing an additional control mechanism of EMT and tumor progression. To better understand the participation of Snai1 and LOXL2 molecules, Peinado et al. have performed in-depth in vitro and in vivo studies of $\mathrm{HaCa} 4$ cells with silenced expression of Snail or LOXL2. These results suggest that LOXL2 influences the Snail-dependent invasion properties and, perhaps, the Snai1-prosurvival action, but, in addition, LOXL2 has specific functions in the negative control of the epidermal differentiation program, apparently through the direct or indirect regulation of Snai1-independent target genes.

Subsequent mechanistic studies showed that LOXL2 could activate both the Snai1/E-cadherin and Src kinase/ focal adhesion kinase (Src/FAK) pathways. However, secreted LOXL2 induced gastric tumor cell invasion and metastasis exclusively via the Src/FAK pathway but not the Snai1/E-cadherin pathway. ${ }^{2}$

\section{Dajiang Li, PhD, Tianyu Li, PhD, and Shuguang Wang, PhD}

Institute of Hepatobiliary Surgery of PLA, Southwest Hospital, Third Military Medical University, Chongqing, People's Republic of China

e-mail: sgwang90@yahoo.com

Published Online: 20 July 2010

(C) Society of Surgical Oncology 2010

\section{REFERENCES}

1. Li T, Li D, Cheng L, Wu H, Gao Z, Liu Z, et al. Epithelialmesenchymal transition induced by hepatitis $C$ virus core protein in cholangiocarcinoma. Ann Surg Oncol. 2010;17:1937-44. doi: 10.1245/s10434-010-0925-3.

2. Peng L, Ran YL, Hu H, Yu L, Liu Q, Zhou Z, et al. Secreted LOXL2 is a novel therapeutic target that promotes gastric cancer metastasis via the Src/FAK pathway. Carcinogenesis. 2009;30: 1660-9.

3. Peinado H, Moreno-Bueno G, Hardisson D, Pérez-Gómez E, Santos V, Mendiola M, et al. Lysyl oxidase-Like 2 as a new poor prognosis marker of squamous cell carcinomas. Cancer Res. 2008;68:4541-50.

4. Hollosi P, Yakushiji JK, Fong KS, Csiszar K, Fong SF. Lysyl oxidase-like 2 promotes migration in noninvasive breast cancer cells but not in normal breast epithelial cells. Int $J$ Cancer. 2009;125:318-27. 